\title{
CONDOMÍNIOS INDUSTRIAIS E EMPRESARIAIS NO BRASIL. A INDÚSTRIA AUTOMOBILÍSTICA E OS NOVOS ESPAÇOS PRODUTIVOS EM CAMPINAS (SP)
}

\author{
AURO APARECIDO MENDES ${ }^{1}$
}

\begin{abstract}
Resumo - O sistema produtivo globalizou-se, com vantagens comparativas dinâmicas ou competitivas, que geram novas relações de trabalho e de produção. Espaços integrados com capacitações técnicas, logísticas, de serviços, na forma de condomínios industriais têm possibilitado a integração entre empresas dos mais variados ramos ou setores da atividade econômica que, no passado, estavam dispersos geograficamente. $\mathrm{O}$ espaço, cada vez mais conectado, articulado e integrado, é essencial para o funcionamento das indústrias e das atividades criativas. O objetivo deste trabalho é mostrar a importância e tipologias dos condomínios industriais e empresariais na Região Metropolitana de Campinas (São Paulo, Brasil), que tem sido pioneira na implantação e concentração de atividades econômicas, e quais as condições gerais para a produção e a reprodução do capital em tais espaços produtivos.
\end{abstract}

Palavras-chave: Condomínios industriais e empresariais, inovação, reestruturações produtivas, Brasil.

\begin{abstract}
INDUSTRIAL AND BUSINESS PARKS IN BRAZIL. THE AUTOMOBILE INDUSTRY AND NEW PRODUCTIVITY SPACES IN THE REGION OF CAMPINAS (STATE OF SÃO PAULO). The production system has been globalized with dynamic or competitive comparative advantages, generating new working and production relationships. Industrial parks with technical, logistical and service capabilities have enabled, in fairly creative ways, the integration between different companies or economic activity sectors, which used to be geographically dispersed. The new productivity space is increasingly connected, articulated and integrated, and it currently plays an essential role for the operation of industries and creative activities. This paper aims to show the importance of the industrial and business parks in Brazil, their types and how the general conditions for the production and reproduction of capital occur notably in the metropolitan region of Campinas (a city of São Paulo State - Brazil), which has been a pioneer in the deployment and concentration of economic activities in such productive spaces.
\end{abstract}

Keywords: Industrial and business parks, innovation, productivity reorganization, Brazil.

Recebido: Janeiro 2013. Aceite: Julho 2013.

1 Professor Adjunto do Departamento de Geografia, IGCE-UNESP - Rio Claro (SP), Brasil. E-mail: auromendes@uol.com.br 
Résumé - LES CONDOMINIUMS INDUSTRIELS ET D'ENTREPRISE. INDUSTRIE AUTOMOBILE ET NOUVEAUX ESPACES PRODUCTIFs À CAMPINAS (SÃo PAUlO-BRÉSIL). Le système productif, qui s'est " globalisé ", s'accompagne d'avantages compétitifs, qui ont donné naissance à de nouvelles relations de production et de travail. Des espaces intégrés en condominiums industriels, avec de nouvelles capacités techniques et de services, ont amélioré l'intégration des entreprises, qui étaient auparavant géographiquement dispersées. Ces espaces, toujours mieux connectés, articulés et intégrés, sont essentiels pour le fonctionnement des industries et des autres activités créatrices. L'objectif de cette étude est de faire ressortir l'importance et le type de condominiums industriels et d'entreprise de la Région de Campinas (São Paulo, Brésil), pionnière en ce domaine, et de montrer les conditions générales de production et de reproduction du capital dans ce type d'espace productif.

Mots-clés: Condominiums industriels et d'entreprise, innovation, nouvelles relations productives, Brésil.

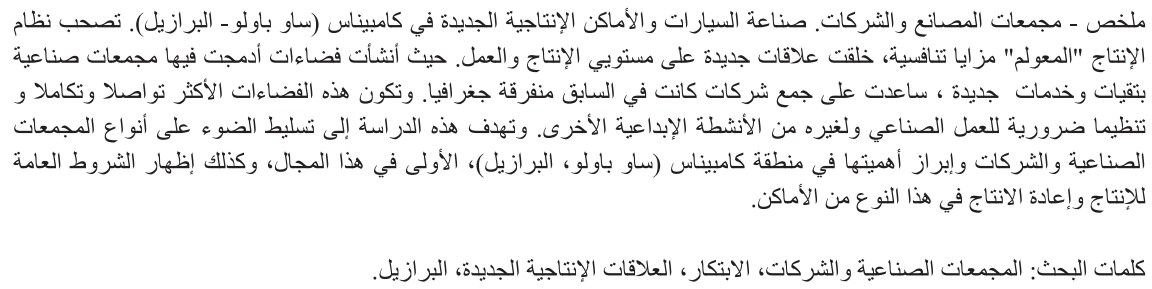

\section{INTRODUÇÃO}

O presente trabalho apresenta alguns resultados de uma ampla pesquisa que venho realizando sobre os condomínios industriais e empresariais no Brasil nos últimos 10 anos.

A empresa horizontal apresenta os seguintes aspectos: organização em torno do processo, não da tarefa; hierarquia horizontal; gerenciamento em equipe; medida do desempenho pela satisfação do cliente; recompensa com base no desempenho da equipe; maximização dos contatos com fornecedores e clientes, informação e treinamento de funcionários em todos os níveis. Para operar na nova economia global, caracterizada pela onda de novos concorrentes que usam tecnologias de ponta e mostram capacidade de redução de custos, as grandes empresas tiveram de tornar-se principalmente mais "flexíveis".

$\mathrm{O}$ advento da indústria de alta tecnologia, ou seja, a indústria com base na microeletrônica e assistida por computadores, introduziu uma nova lógica de localização industrial. As empresas eletrônicas, produtoras dos novos dispositivos da tecnologia da informação, também foram as primeiras a utilizar a estratégia de localização possibilitada e exigida pelo processo produtivo baseado na informação. Esse espaço caracteriza-se pela capacidade organizacional e tecnológica de separar o processo produtivo em diferentes localizações, ao mesmo tempo que reintegra sua 
unidade por meio de conexões de telecomunicações e da flexibilidade e precisão resultante da microeletrônica na fabricação de componentes. Além disso, devido à singularidade da força de trabalho necessária para cada estágio e às diferentes características sociais e ambientais próprias das condições de vida de segmentos profundamente distintos dessa força de trabalho, é sugerido um espaço geográfico específico para cada fase do processo produtivo, promovendo a desintegração espacial da produção.

De acordo com Castells (1999: 418), o novo espaço industrial não representa o fim das antigas paisagens fabris já estabelecidas, mas a possibilidade de se abrir a novas funções e de se integrarem indústrias caracterizadas por alta tecnologia. $\mathrm{O}$ novo espaço industrial é organizado em torno de fluxos de informações que, ao mesmo tempo, reúnem e separam seus componentes territoriais, dependendo do ciclo das empresas. E, à medida que a lógica da fabricação da tecnologia da informação vai passando dos produtores de equipamentos de tecnologia da informação para os usuários destes dispositivos em toda a esfera da indústria, também a nova lógica espacial se expande, criando uma multiplicidade de redes industriais globais, cujas intersecções e exclusões mudam o próprio conceito de localização industrial de fábricas para fluxos industriais.

A desintegração vertical de uma empresa ocorre quando as diferentes etapas do processo produtivo não se efetivam na mesma empresa. A tendência à desintegração vertical tornou-se muito comum, o que explica a multiplicação de pequenas e médias empresas. A organização da produção - integrada ou desintegrada - depende da economia de escopo.

Assim sendo, verifica-se que as mudanças geográficas dos espaços de produção coincidem com as mutações maiores da organização da produção, que por sua vez são provocadas pelas exigências do novo regime de acumulação.

Faz-se mister salientar que o processo de reprodução do capital dessa "nova ordem capitalista" é caracterizado por uma série de imbricações de comando, de fazer, de obedecer, de depender, entre outras, que acabam intensificando as relações entre o todo e as partes, entre o lugar e o global. Trata-se, portanto, do poder das grandes empresas ("verticalidades") no desenvolvimento territorial.

As relações produtivas na atividade industrial geram novos recortes territoriais, cujo domínio e poder fogem da esfera nacional. Tais relações exigem um novo entendimento da noção de tempo e de espaço e procuram atender as demandas da própria sociedade.

O trabalho encontra-se estruturado da seguinte forma: depois da presente introdução, a seção II consiste na fundamentação teórica; na seção III são relatadas algumas experiências brasileiras no que concerne à indústria automobilística, que se tem destacado em termos de implantação de novos espaços produtivos; na seção IV são abordados os condomínios industriais e empresariais na Região de Campinas (SP), por seu pioneirismo no Brasil; por último, tecem-se algumas considerações finais. 


\section{ENQUADRAMENTO TEÓRICO}

Em meio a todas as transformações sócio-econômicas e espaciais em curso, é necessário compreender que cada lugar é único, resultado da combinação das relações de dominação, subordinação e interdependência e produzido historicamente.

$\mathrm{O}$ alcance espacial do sistema produtivo globalizou-se, fundamentando-se em vantagens comparativas dinâmicas ou competitivas, gerando novas relações de trabalho e de produção. Dessa forma, as economias locais devem ser entendidas como malhas de uma rede econômica global. Não se podem olvidar, nem negligenciar os nexos que prendem o local ao global e vice-versa. Emergem, assim, novos espaços industriais cada vez mais seletivos, mais "inteligentes", constituindo o chamado "meio técnico-científico-informacional" (Santos, 1994).

O "meio técnico-científico-informacional", com seus atributos construídos historicamente, desponta no caso dos condomínios industriais, consórcios modulares e centros empresariais, como uma nova forma espacial, determinando as localizações e selecionando as atividades econômicas.

Os espaços tornam-se seletivos porque nem todos os segmentos produtivos ou gêneros industriais têm condições (financeiras ou outras) de ingressarem nestes locais, por aluguer ou compra de um lote. Tais espaços são seletivos, também, porque possuem normas (emprego de tecnologias limpas, investimentos em Investigação e Desenvolvimento, por exemplo), que regem as empresas instaladas, ou seja, não são todas as empresas que atendem as demandas dessas novas formas espaciais de produção.

Outro aspecto importante que merece ser salientado, além das infraestruturas e dos serviços existentes que possibilitam o funcionamento racional, viável e rentável das empresas instaladas, refere-se à proximidade geográfica que permite não só a agilização da produção, mas ainda, o compartilhamento do conhecimento, do aprendizado e das trocas de experiências e dos serviços disponíveis.

Segundo Lemos (2000), enormes esforços estão sendo empreendidos para tornar os novos conhecimentos apropriáveis. Isto se dá através de interações entre os diferentes agentes econômicos e sociais para difusão e geração de inovações. Essa interação pode ocorrer ao nível de uma empresa, entre empresas, ou entre empresas e distintas organizações de ensino e pesquisa.

$\mathrm{Na}$ era do conhecimento ou do aprendizado, o grande desafio é também transformar as informações em conhecimento, conforme Lojkine (1995), Foray e Lundvall (1996), Castells (1999), Cassiolato e Lastres, (1999), entre outros.

Os conhecimentos empregados na geração de inovações podem ser tanto codificados como tácitos, públicos ou privados e tornam-se cada vez mais inter-relacionados. O conhecimento codificado pode ser facilmente transferível através do uso de novas tecnologias, mas o conhecimento não codificado ou tácito, só se transfere por meio da interação social, face a face, que se dá de forma localizada em organizações e locais específicos. Assim sendo, faz-se mister considerar os canais e as diferentes conexões em que ocorre a transmissão das informações e do conheci- 
mento que podem existir localmente, devido à proximidade das empresas e outras instituições envolvidas, bem como através dos nexos que extrapolam o local, vinculando a produção do conhecimento a outras esferas espaciais.

Em importante estudo sobre conhecimento, inovação e território, Vale (2009) identifica duas abordagens que merecem ser ressaltadas:

a) Uma abordagem que privilegia a proximidade espacial nas dinâmicas inovadoras nos territórios, valorizando, portanto, os contextos sócio-territoriais (linguagens, normas, valores culturais comuns, entre outros). Essa abordagem é utilizada nas investigações realizadas por Storper e Venables (2002) que consideram o buzz local, ou seja o ambiente vibrante, como algo fundamental para a produção do conhecimento e da aprendizagem. Outros autores, como Gertler (1995) e Morgan (2004), advogam a importância da proximidade geográfica e da dimensão tácita do conhecimento localizado nas dinâmicas inovadoras.

b) Outra abordagem refere-se às redes de inovação sem uma delimitação espacial fixa, de natureza multi-escalar, sendo mencionada por Henderson et al. (2002), Torre e Rallet (2005), Vale e Caldeira (2007). São mudanças na organização industrial, não atreladas exclusivamente, à proximidade espacial. Nesse caso, os canais de comunicação com o exterior, designados por pipelines, exercem um papel de extrema importância para obtenção e transmissão de conhecimentos.

Vale (2009: 16) propõe a superação das duas abordagens teóricas acerca da análise dos processos da inovação, uma vez que os modelos de inovação e de aprendizagem meramente locais não captam as dinâmicas do conhecimento, que devem ser consideradas em termos multi-territoriais.

Por outro lado, os condomínios industriais e empresariais, dotados de infraestruturas adequadas para a geração de informações e apropriação de conhecimentos constituem, atualmente, um novo espaço diferente das antigas aglomerações industriais e dos atuais arranjos produtivos locais (Mendes, 1997). A imersão das empresas neste ambiente impregnado de conhecimentos (tácitos ou codificados) e de saberes, impulsiona os processos inovadores, contribuindo para a disseminação do conhecimento e para a diminuição das incertezas. Espaços dotados de capacitações técnicas, logísticas e de serviços, na forma de condomínios industriais e centros empresariais tem possibilitado a integração entre empresas dos mais variados ramos ou setores da atividade econômica que, no passado, encontravam-se dispersos geograficamente.

Conforme Méndez (2008: 168) a inovação é um fenômeno altamente seletivo, concentrando-se em alguns ramos produtivos e em territórios que permitem a sua geração e difusão. Tais territórios ou regiões, cuja capacidade de inovar ocorre não de forma isolada ou individual mas de forma coletiva, através de sinergias e de um ambiente empresarial, social e institucional são denominados meios inovadores (Aydalot, 1986; Maillat, 1995) e territórios inteligentes, ou territórios que aprendem (Florida, 1995; Morgan, 1997). 
Os condomínios industriais ou empresariais geralmente estão instalados em territórios considerados inteligentes ou em meios inovadores, compreendendo um parque de fornecedores diretos, comércio e serviços implantados num mesmo espaço. A existência de fornecedores e de outras atividades de apoio, atraem novos investimentos e empreendimentos.

Cabe explicar que no caso dos Condomínios Industriais os fornecedores encontram-se localizados no mesmo terreno (site) em que está instalada a fábrica montadora. No caso dos Consórcios Modulares, os fornecedores encontram-se localizados dentro da fábrica contratante. Existem, também, os modelos híbridos, denominados de Montagem Modular Seqüenciada, que consiste na participação direta dos fornecedores na linha de montagem, compartilhando o mesmo espaço e responsabilidades. Tais experiências demonstram que não existe um caminho único para a rede de fornecedores na indústria. As empresas buscam configurações eficientes, racionais e viáveis, ou seja, novos formatos para agilizar o processo produtivo e a reprodução do capital.

Os condomínios industriais e empresariais existem tanto em regiões metropolitanas quanto em cidades médias, abarcando uma grande variedade de gêneros industriais, podendo ou não serem especializados em um dado ramo produtivo. Os processos produtivos sofisticando-se com o passar do tempo, tornando-se cada vez mais céleres as reestruturações produtivas e organizacionais em tempos de globalização da economia e de "modernidade líquida".

Desde a produção em massa, implementada por Henry Ford por volta de 1915, superando definitivamente a produção artesanal, a atividade industrial torna-se cada vez mais intensiva em tecnologia, conhecimento e pesquisa, ocorrendo, dessa forma, melhoramentos contínuos em todos os segmentos fabris, especialmente no setor automobilístico. Esse ramo fabril, por ser motriz e por assimilar mais rapidamente as inovações tecnológicas em curso, num ambiente extremamente competitivo, acaba sendo o exemplo mais emblemático das transformações em curso na atividade industrial.

O forte aumento da concorrência no setor automóvel tem levado as firmas a buscarem estratégias que otimizem a produção de veículos, mas, também, a novas estratégias logísticas e locacionais. Na busca de um modelo de organização fabril ideal os esforços têm-se concentrado em pesquisa e desenvolvimento, acompanhado, obviamente, de um grande aporte de capitais.

Assim sendo, nos novos espaços industriais observa-se uma mudança em relação ao paradigma taylorista/fordista de produção para um novo padrão caracterizado pelo uso intensivo de novas tecnologias entre montadoras e fornecedores, interdependente e correlacionada. Em suma, uma cadeia produtiva integrada.

Com a vinda para o Brasil de montadoras e de investimentos estrangeiros foram sendo estabelecidos novos formatos produtivos. Atividades que fogem do core business das empresas líderes, que impõem ordens, foram repassadas para os fornecedores sistemistas.

Foi no âmbito desta busca por vantagens comparativas federais, estaduais e locais que muitas empresas representativas do grande capital nacional e estrangeiro, 
implantaram-se até mesmo em regiões sem tradição industrial, ou sem experiências em alguns ramos fabris, arrastando, por meio de novas organizações produtivas (condomínios industriais e consórcios modulares), outras empresas parceiras ou fornecedoras. Estabelece-se, assim, nos locais que abrigaram tais aglomerações produtivas, uma trama de relações interindustriais que funcionam, em muitos casos, como verdadeiras "plataformas de produção".

A proximidade espacial entre a montadora e os fornecedores de primeiro nível (sistemistas) possibilita que a montadora transfira para os fornecedores módulos completos dos veículos (modularização). Na busca por maior agilidade no acesso de suprimentos, produção e atendimento aos clientes, a proximidade geográfica permite alterar com rapidez o mix de produção.

A otimização do processo produtivo, com o emprego de novas tecnologias, visa uma organização estratégica, um fluxo contínuo, desde as matérias-primas até o produto final. Neste fluxo, as principais vantagens e diminuição dos custos devem-se essencialmente aos seguintes fatores: (i) redução do tempo e do trabalho no processo produtivo; (ii) melhoramento da qualidade do produto e do espaço físico; (iii) redução do retrabalho e dos níveis de estoque; (iv) redução dos custos diretos e indiretos com mão de obra; (v) compartilhamento das informações e do conhecimento; (vi) proximidade geográfica dos principais fornecedores; (vii) rapidez nas entregas e nas tomadas de decisões; (viii) segurança e confiabilidade entre todos os elos da cadeia produtiva integrada.

Em suma, as alianças estratégicas interfirmas tem por finalidade reduzir, ao mesmo tempo, os custos de transação e de controle.

Esses espaços produtivos, cada vez mais cooperativos e integrados, dotados de infraestruturas e logísticas sofisticadas, possibilitam o funcionamento ágil e racional das empresas. A interação e a cooperação, via fluxo de informações e de conhecimentos entre produtores, usuários, assistência técnica, indústrias correlatas, serviços, instituições de pesquisa são imprescindíveis para a inovação tecnológica e para a descoberta de novos produtos e processos.

Existe, portanto, uma nova lógica espacial, que afeta a localização dos estabelecimentos industriais, marcada pela presença de instituições de pesquisa, de serviços de apoio, de recursos humanos, enfim, de sinergias positivas que fomentam a inovação e a criatividade de todos os participantes. De acordo com Méndez e Caravaca (1996: 192), inovação, indústria e território são três elementos fundamentais para o entendimento dos novos espaços produtivos.

\section{OS NOVOS ESPAÇOS PRODUTIVOS DA INDÚSTRIA AUTOMOBI- LÍSTICA}

A indústria automobilística foi escolhida como exemplo nessa pesquisa para demonstrar as novas formas de organização do espaço produtivo na atividade industrial no Brasil. Nesse sentido esse ramo industrial se desponta em relação aos outros 
gêneros fabris menos intensivos em capital, implantando consórcios modulares, condomínios industriais e montagem modular seqüenciada, inclusive, em regiões sem tradição industrial no setor automotivo, como é o caso da Ford na Bahia.

A Ford, a GM, a Volkswagen e a Renault são os principais exemplos desses novos espaços produtivos no que tange à indústria automobilística brasileira.

Zawislak e Melo (2006) em um importante estudo sobre o complexo automotivo em Gravataí (Rio Grande do Sul), analisa o caso da GM (General Motors) inaugurada em 20 de julho de 2000. Conforme os autores, a GM sempre apresentou historicamente resistência em abandonar a produção em massa. Esta unidade produz atualmente, carros a medida dos desejos dos clientes, só possível porque o sistema de produção está interligado aos sistemas de vendas via internet. O projeto dessa fábrica, a terceira da GM no país e a primeira fora do estado de São Paulo, recebeu em 1977 o nome de Arara Azul (Blue Macaw). Trata-se da fábrica mais moderna da GM no mundo.

A implantação da GM em Gravataí já conta com um complexo automotivo consolidado, com um setor de autopeças diversificado e com tradição em fornecedores especializados principalmente em caminhões e ônibus o que não acontecia em áreas sem tradição industrial - greenfield regions.

A fábrica da GM tem uma estrutura produtiva intensiva em capital e tecnologia, utilizando robôs e linhas de montagem automatizadas. O projecto Arara Azul tem uma cadeia totalmente integrada, na qual a montadora consegue conciliar preço, qualidade e flexibilidade, estabelecendo diferentes tipos de ligações com os fornecedores instalados no mesmo condomínio. Nesta logística integrada, a montadora repassa para os seus parceiros imediatos, partes significativas do processo produtivo. Conseqüentemente, os fornecedores assumem uma postura pró-ativa neste processo, melhorando a qualidade dos produtos e dos serviços disponibilizados. Organizado na forma de condomínio industrial, a GM tem as suas atividades restritas a sua core competence, enquanto os sistemistas, devidamente integrados ao sistema, produzem os diversos módulos. Se, inicialmente, as indústrias eram completas (realizando praticamente todas as etapas do processo produtivo), com os avanços tecnológicos, ocorre a desintegração da produção e a disjunção espacial do sistema produtivo. Com o surgimento de novas formas espaciais (condomínios industriais, consórcios modulares, por exemplo) o espaço torna-se funcional, permitindo a instalação das atividades econômicas num espaço integrado.

Analisando as mudanças ocorridas no projeto original da VW em Resende (Rio de Janeiro), Corrêa (2000: 2-3) comenta que, pela primeira vez, uma fábrica da VW não teria funcionários de mão de obra direta, apenas parceiros, funcionando sob a forma de consórcio modular. De acordo com o autor, com o passar do tempo ocorreram mudanças no projeto original. Na concepção original, os projetistas dividiriam o produto em submontagens, ou conjunto de componentes (módulos), cujo fornecimento seria subcontratado completamente, ou seja, a VW não seria responsável por nenhum módulo. A implantação da fábrica de ônibus de caminhões da VW em Re- 
sende (Rio de Janeiro), em 1996, foi feita sob a forma de consórcio modular, conforme a concepção de José Ignácio López de Arriortúa, importante executivo da empresa na época.

Além das empresas modulistas, ocupando o mesmo espaço físico da VW, encontram-se outras empresas especializadas que dão suporte nas seguintes áreas: logística, alimentação, limpeza, segurança, etc., além dos fornecedores selecionados que se encontram instalados no mesmo prédio. Esse formato de organização da produção é justamente a radicalização de "subcontratar tudo". Neste caso o modelo de consórcio modular muito se assemelha a uma "empresa vazia" (hollow company), que subcontrata todas as atividades produtivas e importantes competências. Demonstrando, mais uma vez, que somente num espaço integrado é possível uma empresa funcionar nestas condições, subcontratando outras indústrias e terceirizando os seus serviços. No caso da produção de caminhões, a empresa assumiu as atividades de coordenação (planejamento, engenharia, controle de qualidade, etc.), subcontratando as atividades produtivas propriamente ditas. Nesse processo de subcontratação os parceiros (modulistas) acabam detendo o conhecimento e aprendendo mais sobre o produto que está sendo produzido do que a própria empresa contratante.

Observa-se, portanto, que, no Brasil, principalmente a partir de 1990, vários espaços produtivos totalmente integrados na forma de condomínios industriais (GM e Renault), consórcio modular (VW) e montagem modular seqüenciada (Ford) e consórcios modulares híbridos, emergem organizando as atividades industriais, mormente no ramo automobilístico, exemplificados na figura 1.

Verifica-se na figura 1 que, no estado de São Paulo, não existem indústrias automobilísticas funcionando no formato de condomínios industriais, consórcios modulares, ou montagem modular seqüenciada.

Em outubro de 2001 entrou em operação na Bahia o maior investimento industrial automobilístico, feito até então pela Ford em todo mundo. Foi aplicado no Projeto Amazon, em Camaçari, que inclui o desenvolvimento de uma nova linha de veículos, um investimento de cerca de US\$ 1,9 bilhão, segundo os dados da Agência de Fomento do Estado da Bahia- Desenbahia, 2002.

O Projeto Amazon consistiu numa estratégia de expansão da Ford na produção de veículos em países emergentes. A implantação da Ford no Brasil decorreu das condições favoráveis do Regime Automotivo Brasileiro, implementado em 1997. Essas condições, oferecidas na época por meio de concessão de expressivos incentivos públicos, foram imprescindíveis para a instalação da fábrica no Brasil.

A Ford inicialmente estava interessada em instalar a fábrica no estado do Rio Grande do Sul. Foi para a Bahia que, embora, não tivesse tradição no setor automobilístico, oferecia incentivos fiscais e financeiros, infraestrutura e localização geográfica estratégica, o que corrobora as articulações ocorridas no espaço na consolidação dessa nova forma de organização da produção. Fica evidenciado, também, o papel do Estado, não mais como indutor do desenvolvimento territorial, mas como facilitador dos empreendimentos econômicos. 


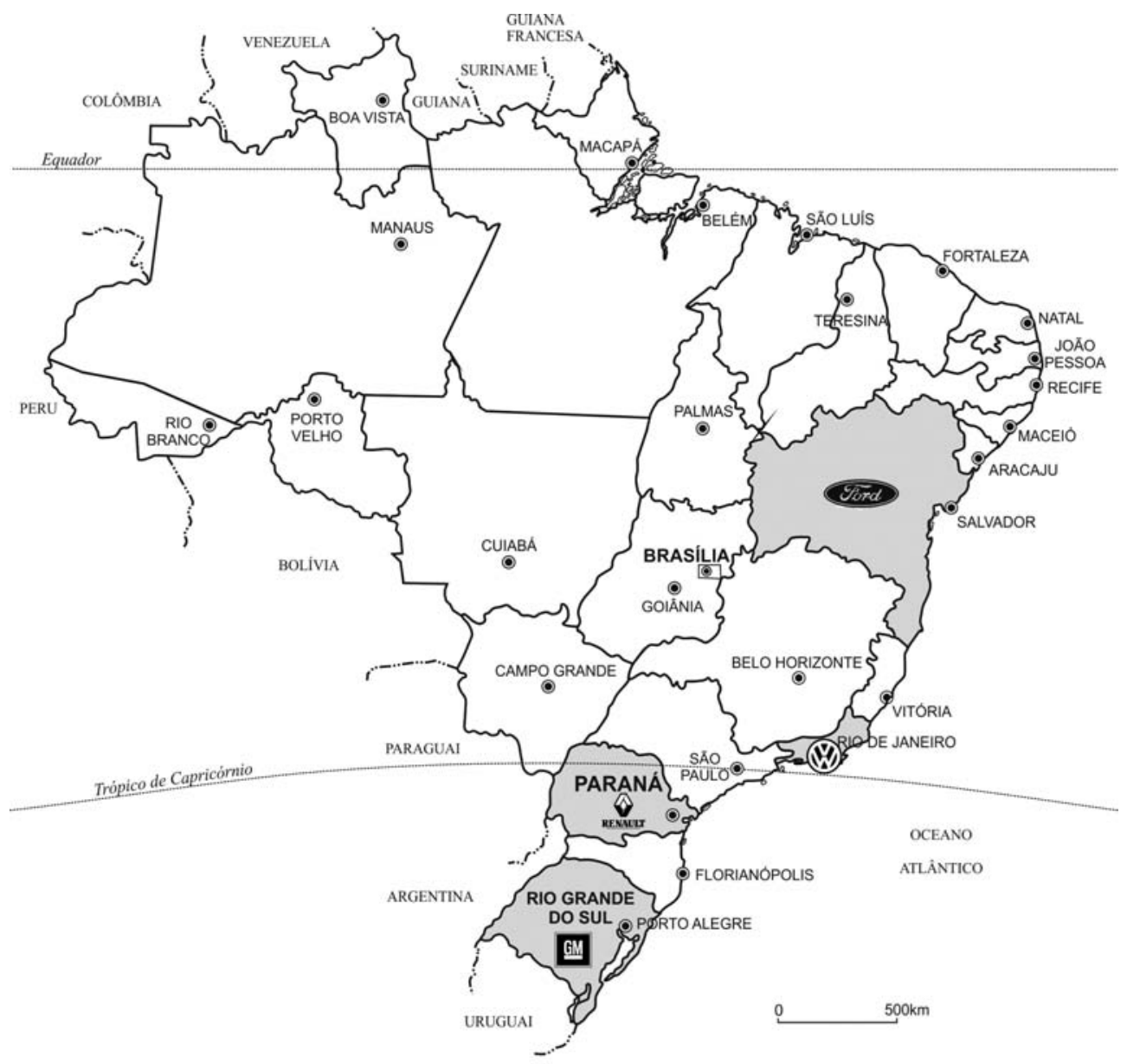

Condomínio Industrial da Renault (Paraná)

될 Condomínio Industrial da General Motors do Brasil (Rio Grande do Sul)

(40) Consórcio Modular da Wolkswagen (Rio de Janeiro)

Montagem Modular Seqüenciada da Ford (Bahia)

Fig. 1 - Novos espaços produtivos no Brasil. Exemplos de indústrias automobilísticas.

Fig. 1 - New Productive Spaces in Brazil: Examples of Automobile Industry.

Em importante estudo sobre a implantação da Renault no estado do Paraná, Pinto e Meza (2003: 332), explicam que a empresa inseriu-se no formato de firma-rede por estabelecer relações cooperativas e de Investigação e Desenvolvimento (I\&D) com outras empresas e fornecedores. Muitas atividades, antes desenvolvidas unicamente pela empresa, estão sendo externalizadas e compartilhadas com os fornecedores. Estes fornecedores (4 empresas), segundo os autores, estão localizados no próprio parque industrial da Renault, o que caracteriza uma organização do tipo condomínio industrial. 
Outro aspecto importante é que os fornecedores são selecionados através de condições impostas pela montadora. Entre elas merecem destaque: a) certificação de qualificação, analisada pela engenharia e pela área de qualidade da montadora; b) capacidade financeira para evitar riscos, descontinuidades de fornecimento e atualização tecnológica e c) preço.

Os autores comentam, ainda, que as atividades de I\&D tem um papel de precípua importância como fonte de inovação. A Renault conta com um centro de I\&D de produtos denominado de Technocentre, em Paris, inaugurado em 1988, empregando mais de 7000 especialistas. Neste centro, são feitas as inovações do processo e do produto. Na unidade produtiva do Paraná, podem existir inovações, mas só de processos, como por exemplo, diminuição do desperdício na estamparia pela inserção de uma máquina local, ou na inovação de um processo produtivo novo (Pinto e Meza, 2003: 334).

Com base nos estudos de casos que foram expostos, verifica-se que todas as empresas automobilísticas estrangeiras implantadas em diferentes regiões do Brasil, funcionam dentro do paradigma de "especialização flexível" de produção "enxuta" (lean production), utilizando tecnologias de ponta, de última geração, com emprego intensivo de capitais em I\&D.

Nesta disputa entre empresas e entre fornecedores, nem todas conseguem se instalar nos condomínios industriais ou consórcios modulares, aparecendo, então, as "empresas ganhadoras" e as "empresas perdedoras". As empresas selecionadas por tais espaços são aquelas em condições de funcionarem em um "meio técnico-científico-informacional", em um meio inovador, usufruindo, por conseguinte, dos conhecimentos tácitos ou codificados existentes e das condições gerais para a produção e a reprodução do capital. Todavia, cabe esclarecer que o formato de condomínios industriais e empresariais não é uma exclusividade do setor automobilístico, uma vez que tais espaços produtivos abrigando outros ramos fabris ou de serviços tem surgido de forma expressiva notadamente na Região de Campinas (SP).

\section{CONDOMÍNIOS INDUSTRIAIS E EMPRESARIAIS NA REGIÃO DE CAMPINAS}

A Região Metropolitana de Campinas e Entorno (no estado de São Paulo) tem sido pioneira na instalação de condomínios industriais e empresariais, podendo ser especializados em um determinado ramo industrial ou mistos envolvendo vários gêneros industriais, serviços e atividades criativas (publicidade, design, entre outras).

A concepção, construção e administração de tais condomínios tem sido realizada por grandes grupos e corporações imobiliárias, que vendem ou fazem a alocação dos terrenos às grandes empresas.

Historicamente, a cidade de Campinas foi transformando-se numa cidade produtora de bens materiais em uma região metropolitana lócus da circulação e de consumo de bens simbólicos e informacionais. Campinas foi criada em 1774 e a sua 
economia nesta época era baseada no plantio de cana e na produção do açúcar. Comparativamente a produção de cana-de-açúcar na região era inferior ao volume de exportações de outras regiões do país, como da Região Nordeste, por exemplo. Rapidamente o cultivo do café se despontou e assumiu, ainda naquele século, o primeiro lugar na produção regional. Em 1868, com a inauguração da Companhia Paulista de Estradas de Ferro, ligando Campinas a Jundiaí e, posteriormente, à capital e ao Porto de Santos, Campinas passou a ser o maior entroncamento ferroviário do Império.

As formas pretéritas de organização do espaço deixam "fixos" que, segundo Santos (1996), constituem "rugosidades" que interagem com as formas atuais. $\mathrm{Na}$ cidade, verifica-se, portanto, conforme o mesmo autor, a "complementaridade de atividades e de funções". A economia cafeeira desenvolveu-se, sem inibir a diversificação de outras atividades econômicas relacionadas com a agropecuária e a agroindústria.

No período de 1930-1960, a economia de Campinas era marcadamente industrial e o seu comércio bastante diversificado, consolidando-se como o mais importante centro regional do estado de São Paulo. Com o dinamismo ocorrido na região de Campinas desenvolveram-se vários setores da atividade econômica, realçando, cada vez mais, a sua posição de destaque no processo de atração de novos investimentos, de mobilidade populacional e de concentração industrial no espaço urbano paulista. Vários fatores contribuíram para tornar a Região Metropolitana de Campinas um espaço singular para o desenvolvimento de atividades industriais, dentre outras, intensivas em tecnologia e conhecimento. Obviamente, que somente em um "meio técnico-científico-informacional" tais atividades tiveram condições de se desenvolverem de forma plena e rentavelmente.

Na década de 1970, a região de Campinas foi a que mais recebeu investimentos através do processo de desconcentração industrial ocorrido a partir da Região Metropolitana de São Paulo, com a instalação de grandes e importantes empresas estrangeiras no município.

No interior do estado de São Paulo é a região do Entorno metropolitano (formado pelos municípios situados num raio de aproximadamente $200 \mathrm{Km}$, a partir da Região Metropolitana de São Paulo) que, historicamente, tem apresentado a maior concentração industrial. O Entorno metropolitano, na verdade, nada mais é do que o conjunto formado pelos municípios mais industrializados das regiões administrativas de Campinas, Vale do Paraíba, Litoral e Sorocaba (Mendes, 1991).

A Região Metropolitana concentra importantes instituições, reconhecidas nacional e internacionalmente como centros de excelência na geração de conhecimentos científicos e tecnológicos. Conta, também, com mão de obra qualificada para as atividades inovativas. Daí o desenvolvimento, na região, de indústrias de alta tecnologia, principalmente aquelas relacionadas a Tecnologias de Informação e Comunicação (TIC).

É neste contexto, neste ambiente industrial, neste meio inovador, neste "território inteligente", no Vale do Silício Brasileiro, que os condomínios industriais eempresariais começam a surgir, a partir da década de 1990, na Região Metropolitana de 
Campinas (Mendes, 2007). Merece enfatizar que tais condomínios que surgem na Região Metropolitana de Campinas, são pioneiros no Brasil. Foi de facto a partir da década de 1990 que o sector da construção apostou nos projetos de condomínios industriais e empresariais.

Assim como o endereço das indústrias durante muito tempo foram os distritos industriais - áreas fabris dotadas de infraestruturas necessárias para implantação e funcionamento das atividades industriais no Brasil - o novo negócio imobiliário das empresas construtoras e incorporadoras imobiliárias são os condomínios industriais e empresariais (fig. 2).

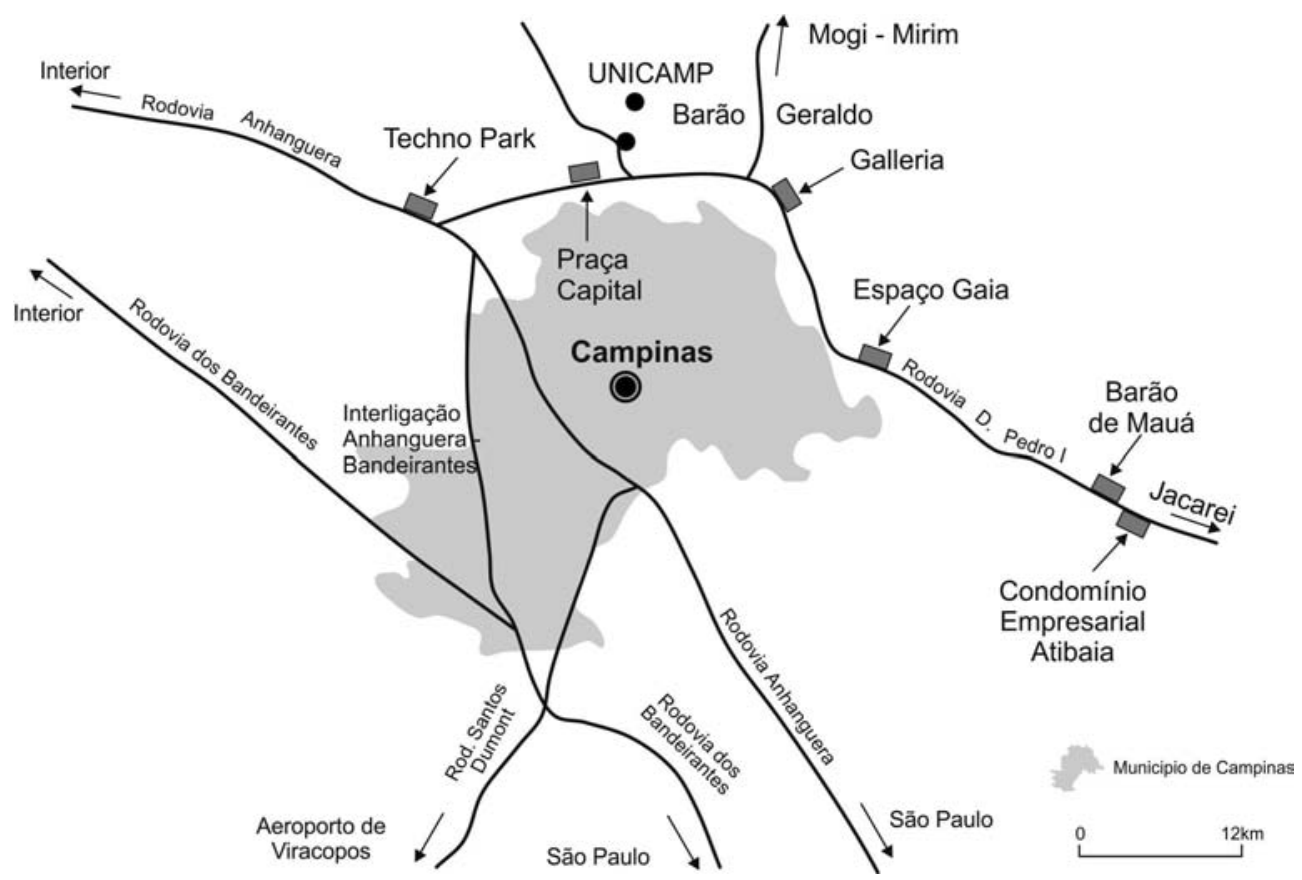

Fig. 2 - Condomínios industriais e empresariais em Campinas (SP) e entornos.

Fig. 2 - Industrial and business condominium in Campinas (São Paulo State-Brazil) and surroundings.

O primeiro a surgir na Região Metropolitana de Campinas foi o Techno Park localizado no entroncamento das Rodovias Anhangüera (km 104), Bandeirantes e Dom Pedro I - importantes rodovias no estado de São Paulo. Este condomínio foi inaugurado em agosto de 1999, em área pertencente ao Grupo DPaschoal. É o primeiro condomínio empresarial no Brasil projetado para receber indústrias de alta tecnologia e não poluentes, centros de distribuição, call-centers, centros comerciais e outros tipos de serviços.

O Condomínio Empresarial Atibaia (CEA) encontra-se estrategicamente localizado à $60 \mathrm{~km}$ de São Paulo e à $35 \mathrm{~km}$ de Campinas, no centro de importante malha viária interligada às principais rodovias estaduais e federais, atingindo com rapidez 
os mais importantes centros consumidores do país. Aí encontram-se instaladas importantes unidades produtivas de alta tecnologia que utilizam as seguintes infraestruturas e serviços: segurança, logística, sala de reuniões, cafeterias, restaurantes, entre outros.

Considerando a qualidade de vida no município e a sua excelente localização o CEA, tem a sua imagem atrelada aos atributos do local. Se no passado o espaço era identificado pelas indústrias nele instaladas, atualmente, as empresas e os condomínios industriais procuram ter a sua imagem associada ao espaço.

O Brasilian Business Park (BBP) é uma holding do grupo MV Incorporações (cujos capitais e a sede do grupo são atibaienses) responsável pela edificação, incorporação, consultoria e administração dos seguintes Condomínios Empresariais: CEA, Barão de Mauá e Espaço Gaia.

Estando o CEA esgotado, ou seja, sem espaço para abrigar novas indústrias, o BBP está construindo outros condomínios na região, tais como o Condomínio Empresarial Barão de Mauá, em frente ao CEA (2 km), com $500000 \mathrm{~m}^{2}$ e o Espaço Gaia, em Jarinu, a aproximadamente $3 \mathrm{~km}$ do CEA, com $700000 \mathrm{~m}^{2}$. Todos os condomínios em construção encontram-se localizados num raio de $20 \mathrm{~km}$ de distância do CEA, desfrutando das vantagens competitivas e locacionais do lugar.

Existem, ainda, em Campinas outros condomínios empresariais que não abrigam indústrias, mas serviços especializados na área de saúde ou de consultorias e atividades criativas, tais como: publicidade, software, entre outras. Entre eles, merecem destaque o Galleria Office Park e o Condomínio Praça Capital.

No complexo Galleria Office Park encontram-se instaladas várias empresas de alta tecnologia que utilizam os seguintes serviços: auditórios, segurança, sala de reuniões, entre outros. As razões que explicam esses investimentos são a existência de condomínios residenciais de alto padrão próximos ao condomínio empresarial, shoppings, proximidade das rodovias, um ambiente buzz, acessibilidade ao Aeroporto Internacional de Viracopos, entre outras.

Inaugurado em 2008, o Condomínio Praça Capital é um Complexo Empresarial baseado em um conceito inovador de Empreendimento Múltiplo, composto de salas comerciais e lojas de conveniência, sendo concebido com a proposta de integração de seus ocupantes, e de promover um espaço de bem-estar e segurança a todos os seus usuários. Implantado em uma área total de $51587 \mathrm{~m}^{2}$, é composto de 13 prédios e 4 quiosques, totalizando assim 547 unidades, sendo destas 63 lojas destinadas à alimentação, prestação de serviços ou comércio. Somam-se a estas instalações áreas para eventos e um estacionamento para 800 veículos. Possui diversas empresas e atividades, de diferentes áreas de atuação, como médica e odontológica, centro esportivo, alimentação, logística, comércio exterior, desenvolvimento de software, arquitetura. Muitos outros condomínios industriais e empresariais encontram-se em construção na Região Metropolitana de Campinas, conferindo a Campinas uma posição de destaque e de vanguarda no cenário nacional. 


\section{CONSIDERAÇÕES FINAIS}

Os condomínios industriais e empresariais são espaços corporativos e cooperativos que logisticamente permitem o funcionamento racional das grandes empresas e a reprodução do grande capital. O espaço torna-se integrado gerando a coordenação e articulação das atividades econômicas.

Os condomínios industriais e empresariais são, atualmente, um produto imobiliário colocado no mercado no meio inovador e em "territórios inteligentes". Proporcionam as condições para criar empresas cada vez mais competitivas.

Criam-se novas relações espaço/indústria e espaço/empresa permeadas por aportes tecnológicos, informacionais e de serviços, que permitem a eficiência de todas as empresas instaladas. No condomínio o empresário não busca mais a localização ideal ou ótima para o seu capital. O condomínio é de per si, o lugar perfeito para a produção e a reprodução do capital.

Neste espaço, todas as atividades que fogem do core business das empresas instaladas são de responsabilidades dos administradores do condomínio.

A indústria automobilística no Brasil por ser um ramo caracterizado por rápidas mutações, inovou organizando o seu espaço produtivo sob a forma de condomínios industriais, consórcios modulares, e montagem modular seqüenciada, rompendo com os antigos padrões locacionais. Tal fato só foi possível devido aos avanços tecnológicos ocorridos que possibilitaram maior flexibilidade nos fluxos, nas sinergias e nas transações entre as empresas. Dessa forma, torna-se possível instalar condomínios industriais, por exemplo, fora do estado de São Paulo (conhecido por sua concentração industrial), buscando novas vantagens competitivas.

Contudo, no estado de São Paulo ganha destaque o número crescente de condomínios industriais que se concentram na Região de Campinas. Esses espaços tem representado para muitos empresários a localização "ótima", "ideal" para a instalação de suas fábricas que se apropriam das condições gerais para a reprodução do capital.

A Região de Campinas destaca-se, ainda, por ser pioneira na implantação de condomínios empresariais que vem sendo ocupados por escritórios de importantes empresas e serviços especializados que desfrutam das infraestruturas sofisticadas existentes e da localização estratégica.

Os condomínios industriais e empresariais revelam, portanto, que o espaço não é desarticulado ou fragmentado. O espaço articulado e integrado tornou-se, logisticamente, inteligente, ágil e inovador.

\section{AGRADECIMENTOS}

Agradeço o importante trabalho realizado pelos revisores da revista. 


\section{BIBLIOGRAFIA}

Aydalot P (1986) Milieux innovateurs en Europe. GREMI, Paris.

Cassiolato J E, Lastres H M M (1999) Globalização \&inovação localizada.Brasília: IBICT/MCT.

Castells M (1999) A sociedade em rede. A era da informação: economia, sociedade e cultura. Paz e Terra, São Paulo.

Corrêa H L (2000) VW Resende: mudanças no projeto original e uma breve avaliação. Anais do III SIMPOI, São Paulo: 1-14.

Foray D, Lundvall B (1996) The knowledge - based economy: from the economics of knowledge to the learning economy. OCDE.

Florida R (1995) Towards the learning regions. Future, 5: 527-536.

Gertler M (1995) Being there: proximity, organization, and culture in the development and adoption of advanced manufacturing technologies. Economic Geography, 71: 1-26.

Henderson J, et al. (2002) Global production networks and the analysis of economic development. Review of International Political Economy, 9: 436-464.

Lemos M B, Diniz C C, Santos F B T, Afonso M A C, Camargo O (2000) Arranjos produtivos locais e as novas politicas de desenvolvimento industrial e tecnológico. (Projeto de Pesquisa). IE/UFRJ, Rio de Janeiro.

Lojkine J (1995) A revolução informacional. Cortez, São Paulo.

Maillat D (1995) Les milieux innovateurs. Sciences Humaines, 8: 41-42.

Mendes A A (2007) Quando o espaço determina a indústria: o exemplo do condomínio empresarial Atibaia. Tese de Livre-Docência. UNESP, Rio Claro.

Mendes A A (1997) Reestruturações locais como efeitos da globalização econômica: uma análise da estrutura produtiva mutante do pólo têxtil de Americana, SP. Tese de Doutorado em Geografia. UNESP, Rio Claro.

Mendes A A (1991) Implantação industrial em Sumaré: origens, agentes e efeitos. Contribuição ao estudo da interiorização da indústria no Estado de São Paulo. Dissertação de Mestrado em Geografia. UNESP, Rio Claro.

Méndez R (2008) Geografia econômica. La lógica espacial del capitalismo global. Editorial Ariel, Barcelona.

Méndez R, Caravaca I (1996) Organización industrial y territorio. Editorial Sintesis, Madrid.

Morgan K (2004) The exaggerated death of geography: learning, proximity and territorial innovation systems. Journal of Economic Geography, 4: 3-21.

Morgan K (1997) The learning region: institutions, innovation and regional renewal. Regional Studies, 5: 491-503.

Pinto H E M, Meza M L F G (2003) Globalização e relações tecnológicas nas empresas multinacionais do setor automobilístico: $\mathrm{O}$ caso $\mathrm{Re}-$ nault do Paraná. InII ECOPAR, 2, Maringá: 317-337.

Santos M (1996) A natureza do espaço. Técnica e tempo. Razão e emoção.Hucitec, São Paulo.

Santos M (1994) Técnica, espaço, tempo. Globalização e meio técnico-científico-informacional. Hucitec, São Paulo.

Storper M, Venables A (2002) Buzz: face-to-face contact and the urban economy. Journal of Economic Geography, 4: 351-370.

Torre A, Rallet A (2005) Proximity and localization. Regional Studies, 39: 47-59.

Vale M (2009) Conhecimento, inovação e território. Finisterra - Revista Portuguesa de Geografia, XLIV(88): 9-22.

Vale M, Caldeira J (2007) Proximity and knowledge governance in localized production systems: the footwear industry the North region of Portugal. European Planning Studies, 15: 531-548.

Zawislak P A, Melo A A (2012) A indústria automotiva no Rio Grande do Sul: impactos recentes e alternativas de desenvolvimento. In Nabuco R M, Neves M A, Neto A M C (eds) Indústria Automotiva. A Nova Geografia do Setor Produtivo. Lamparina Editora, Rio de Janeiro: 105-138. 